Volume 9, No.4, July - August 2020

International Journal of Advanced Trends in Computer Science and Engineering

Available Online at http://www.warse.org/IJATCSE/static/pdf/file/ijatcse202942020.pdf

https://doi.org/10.30534/ijatcse/2020/202942020

\title{
CoCo-Dropping: A Color Composition Extraction of Gamefowl's Dropping Using Image Processing
}

\author{
Alvin Sarraga Alon ${ }^{1}$, Estrelita T. Manansala ${ }^{2}$, Elie Rose C. Francisco ${ }^{3}$, Marites V. Fontanilla ${ }^{4}$, \\ Rolando R. Fajardo ${ }^{5}$ \\ ${ }^{1}$ Technological Institute of the Philippines, Manila Philippines, aalon.cpe@tip.edu.ph \\ ${ }^{2}$ FEU Institute of Technology, Manila Philippines, etmanansala@ feutech.edu.ph \\ ${ }^{3}$ FEU Institute of Technology, Manila Philippines, ecfrancisco0930@ gmail.com \\ ${ }^{4}$ St. Paul University, Quezon City Philippines, mfontanilla@spuqc.edu.ph \\ ${ }^{5}$ Far Eastern University, Manila Philippines, rfajardo@feu.edu.ph
}

\begin{abstract}
Gamefowl owners and cockfighters have a variety of ways to tell whether a gamefowl is battle-ready or not. One of these is through the condition of the gamefowl droppings. A dropping that is not too wet and not too dry indicates that the gamefowl is at its peak condition. This paper presents an image processing based gamefowl dropping's color composition system that aims to recognize a dropping from a peaked gamefowl. This system will make use of a recognition algorithm and a color composition algorithm (using RGB) to solve the problems encountered using the manual method of dropping monitoring. Different samples were used to verify the system's accuracy and based on the analysis, the system was able to get a success rate of $100 \%$. This shows that the system is fully functional and effective in providing a solution to solve the common problem of gamefowl owners and cockfighters.
\end{abstract}

Key words : Color composition, dropping, image processing, gamefowl.

\section{INTRODUCTION}

Between 1965 and 2003, animals have been heavily associated with entertainment due to an increase in leisure time for both men and women [1]. Animal entertainment includes wildlife-watching tourism and blood sport. Despite blood sport being illegal in a lot of countries because of animal cruelty, became prominent [2]. Bullfighting, dogfighting, and cockfighting were some of the most popular forms of blood sport [3]. Cockfighting is known as a tradition that lets two gamecocks fight inside a cockpit, it evolved together with the gamecocks [4]. This game became popular not only in the USA but also in parts of Latin America and Southeast Asia particularly in Indonesia and the Philippines [5]. The combatants, referred to as gamecocks, are specially bred birds, conditioned for increased stamina and strength [6].
Game fowls come in different varieties and there are many different rules for cockfighting [7]. The first documented use of the word game fowl denotes the use of a cock in a game or a sport. In cockfighting, the game fowls are equipped with either metal spurs which are called gaffs, or knives tied to the leg area where its natural spur was partially removed [8].

To ensure that the game fowls are in their best condition before fights, they are being conditioned even months ahead of the scheduled fight [9]. Vitamins are given to improve game fowl health and conditioning activities which are patterned to what is best for that specific game fowl is applied [10]. The training for a gamefowl is not different from how boxers are being trained [11]. A game fowl that is at its best condition may exhibit the following characteristics: the gamecock's face and bottoms are fully red, keeps on moving on its scratch pen, shows active and aggressive behavior, accustomed to noisy and crowded places, and having a head knocking syndrome. Another indicator used by cockfighters to determine battle preparedness is the gamefowl droppings [12].

A normal gamefowl dropping can be on a shade of brown, green, yellow, white, black, or a combination of these colors. Droppings on normal ranges may vary based on the gamefowl diet, time of the year, and overall health [13]. Cockfighters often consider the droppings as an early indication of illness and/or battle preparedness. When closely observed, game fowl droppings are firm, either wet or not. The moisture content in the body of game fowls is crucial especially when fight time is nearing. A dehydrated gamefowl can show signs of weakness and can faint easily while on the other hand, having too much water inside the game fowl's body can make it too slow and may cause bleeding. Therefore, in spotting a battle-ready gamefowl, droppings which are not too dry and not too wet - a firm dropping is observed [14].

Signs and characteristics are being considered in determining whether a gamecock is at its peak condition to fight [15]. A gamecock that is at its best condition may have the following characteristics based on cockfighters' experience: the 
gamecock's face and bottoms are fully red, keeps on moving on its scratch pen, shows active and aggressive behavior, accustomed in noisy and crowded places, and having a head knocking syndrome. The condition of the gamecock droppings is also used as one of the best indicators of a gamecock's readiness for battle.

To make use of the droppings as an indicator for battle preparedness, it must be evaluated the moment it was excreted by the gamefowl. The color composition of the recognized droppings will be extracted for this study. Study of [16]-[20] used also the power of image processing as a tool for data analysis.

\section{METHODOLOGY}

The materials and methods used in this analysis are discussed in this section.

\subsection{Hardware Specifications}

In creating the system, a camera with a maximum photo resolution of 3280x 2464 pixels and with a supported video resolution of 1080p30, 720p60, and 640x480p90 will be used. The use of a camera with an infrared filter for low light applications is also considered. As for processing, Laptop as Acer Aspire E14 E5-473G-304W, with specifications shown in Tables 1 and 2.

Table 1: Computer Hardware Specifications

\begin{tabular}{ll}
\hline & Specifications \\
\hline CPU & Intel Core i3-5005U Dual-core 64-bit @ 2 GHz \\
GPU & NVIDIA GeForce 920M \\
Operating System & Windows 10 \\
Wi-Fi Standard & $\mathbf{8 0 2 . 1 1 ~ a / b / g / n / a c ~}$ \\
RAM & 4 Gb DDR3L SDRAM \\
Internal memory & 1 terabyte \\
Primary Storage Drive Technology & Hard Disk Drive \\
Battery Life & 5 hours \\
Dimensions & $24.9 \times 343 \times 245 \mathrm{~mm}$ \\
\hline
\end{tabular}

Table 2: Camera Hardware Specifications

\begin{tabular}{lc}
\hline & Specifications \\
\hline Image Sensor & 1080p Full HD \\
Video Quality & Up to 2 megapixels and 30fps recording \\
Image Quality & 16 megapixels \\
Interface & USB 2.0 \\
Compatibility & Windows and Mac OS \\
& Wide - angle \\
\multicolumn{2}{c}{ Mountable to both laptops and LCD monitors } \\
\end{tabular}

\subsection{Method}

Figure 1 shows the methodology in determining the colors of an object, the method used the combinations of the colors in
RGB plane by tweaking the values of each RGB channel to get a specific range that encompasses a specific color. Considering that in the image processing of the system it is required to determine the objects' color and its percentage.

The color composition of the droppings will be extracted (limited to brown, green, orange, white, and red). Results will be used for further evaluation of the dropping condition such as determining vitamin deficiencies, illnesses, and others but is not under the scope of this project.

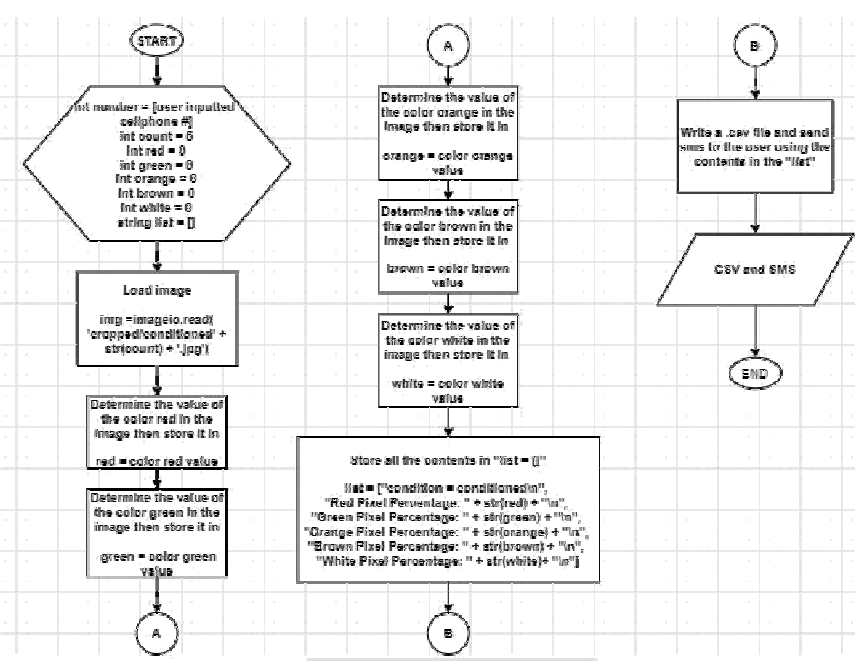

Figure 1: Methodology of CoCo-Dropping

\section{RESULTS AND DISCUSSIONS}

To verify the developed algorithms, different dropping samples were used for the testing as shown in Tables 3 and 4 . The system was able to extract the color composition in terms of their percentage (limited to red, green, orange, brown, and white). However, there are slight differences between the actual colors present in the droppings and the color percentages generated because of the lighting conditions. Dropping conditions can now be monitored easily because the system was able to detect and recognize the droppings from the moment it was excreted by the gamefowl. It is observed in the results of the testing that the system can save images of the recognized droppings, create a CSV file containing values for color composition, and send a notification to the user through SMS.

Table 3: Testing Results

\begin{tabular}{lll}
\hline Test Case & Results & Description \\
\hline & COLOR \\
& COMPOSITION \\
& USING DROPPING \\
& SAMPLE 1 \\
& (BROWN \\
& WELL-LIT) \\
& COLOR \\
& EXTRACTED: \\
& RED - 0\% \\
& GREEN $-0 \%$ \\
& ORANGE $-0 \%$ \\
& BROWN $-35.87 \%$ \\
& WHITE $-20.57 \%$ \\
\hline
\end{tabular}




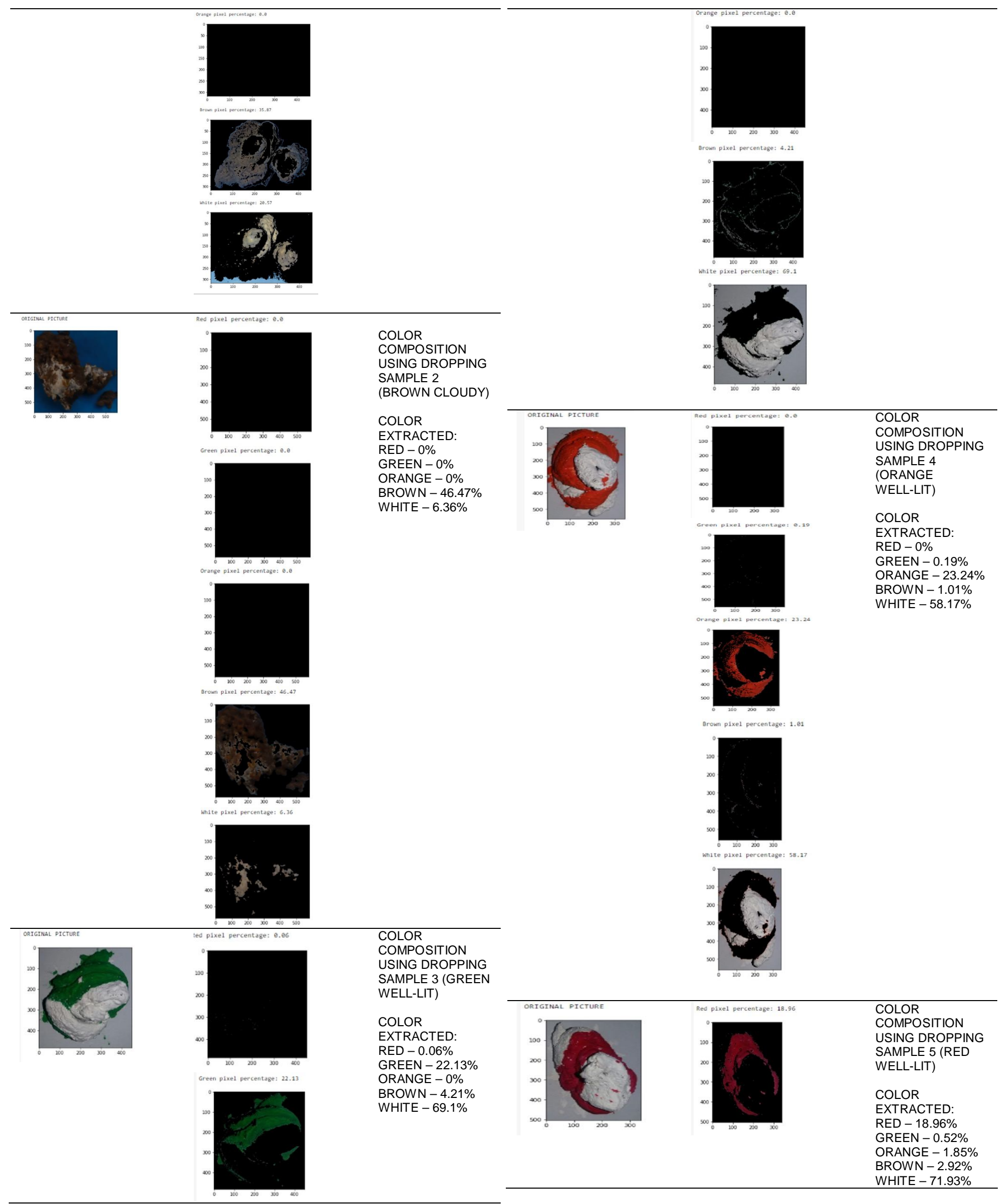




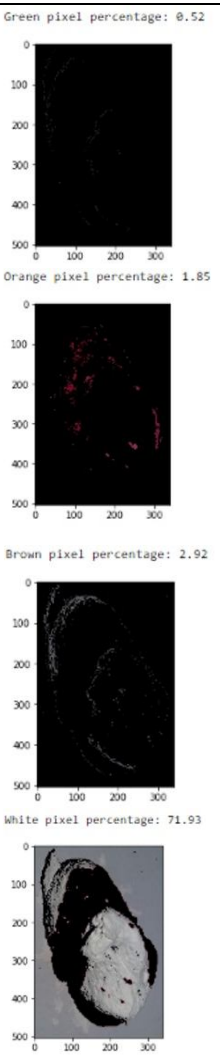

Table 4: User Notification SMS Results

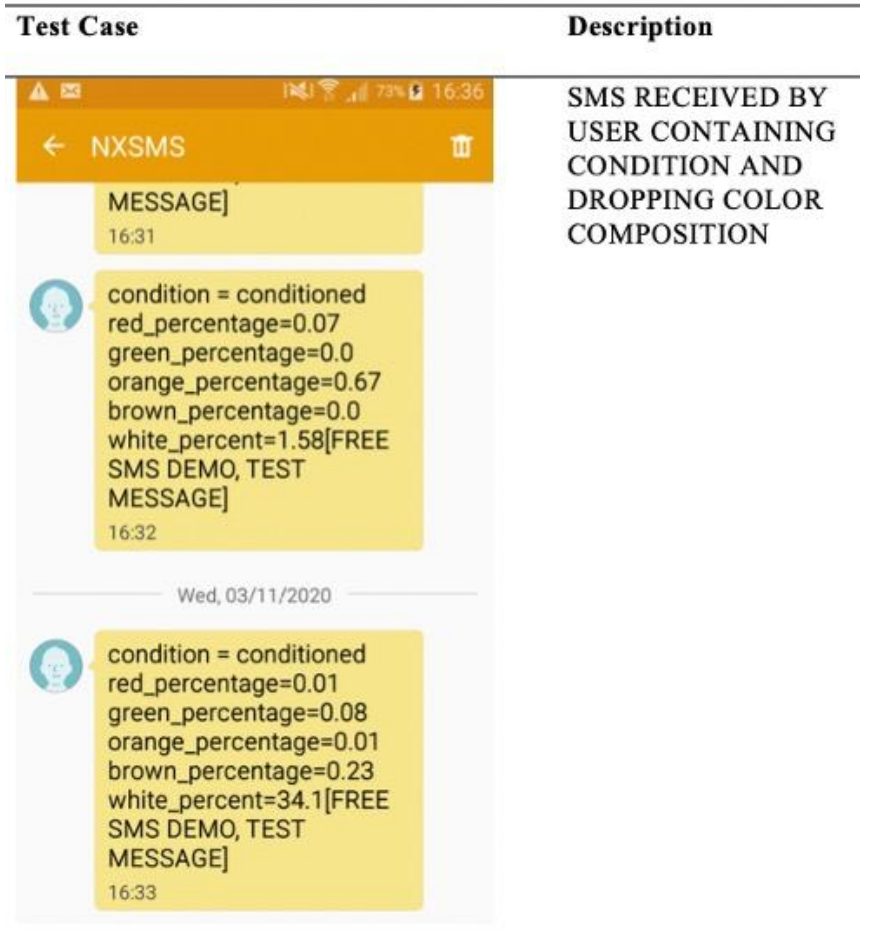

\section{CONCLUSION}

Based on the results of the testing conducted on the developed algorithms, it is clear that the image processing techniques applied in making the system were correct and effective. From the analysis of the results, it can be inferred that the accuracy of detecting and recognizing the droppings' colors depends on the angle at which the camera is placed. The recognition algorithm was able to recognize the dropping because the camera was able to capture a wider scope due to the angle it is placed. As for the color composition, lighting conditions must be considered because how light reflects on the droppings affects the determination of colors. The system was able to perform other operations very well including the saving of the recognized droppings, generation of CSV file containing color composition, and the user notification through SMS.

\section{ACKNOWLEDGEMENT}

The authors wish to share their intense and heartfelt appreciation for the 2nd SEM SY19-20 class of his Data Science Elective. In particular, to the Technological Institute of the Philippines' MR-SUAVE Lab and Microprocessors Lab.

\section{REFERENCES}

1. C. Scanes, Animals in Entertainment, Animals and Human Society, pp. 225-255, 2018. doi: 10.1016/b978-0-12-805247-1.00014-9

2. R. Nóbrega Alves and R. Duarte Barboza, From Roman Arenas to Movie Screens, Ethnozoology, pp. 363-382, 2018. doi: 10.1016/b978-0-12-809913-1.00020-x

3. J. Segura, R. Ventura, M. González and C. Jiménez, Chapter 15 Doping substances in human and animal sport, Handbook of Analytical Separations, pp. 531-566, 2000. doi: 10.1016/s1567-7192(00)80070-4

4. T. Komiyama, K. Ikeo and T. Gojobori, Where is the origin of the Japanese gamecocks?, Gene, vol. 317, pp. 195-202, 2003. doi: 10.1016/s0378-1119(03)00703-0

5. B. Mtileni et al., Diversity and origin of South African chickens, Poultry Science, vol. 90, no. 10, pp. 2189-2194, 2011. doi: 10.3382/ps.2011-01505

6. H. Bi, G. Yi and N. Yang, Increased copy number of SOCS2 gene in Chinese gamecocks, Poultry Science, vol. 96, no. 5, pp. 1041-1044, 2017. doi: $10.3382 / \mathrm{ps} / \mathrm{pew} 391$

7. L. Garber, G. Hill, J. Rodriguez, G. Gregory and L. Voelker, Non-commercial poultry industries: Surveys of backyard and gamefowl breeder flocks in the United States, Preventive Veterinary Medicine, vol. 80, no. 2-3, pp. 120-128, 2007. doi: 10.1016/.j.prevetmed.2007.01.012

8. S. Walker and H. Meijer, More than food; evidence for different breeds and cockfighting in Gallus gallus bones from Medieval and Post-Medieval Norway, Quaternary International, vol. 543, pp. 125-134, 2020. doi: 10.1016/j.quaint.2020.03.008

9. T. Komiyama, K. Ikeo, Y. Tateno and T. Gojobori, Japanese domesticated chickens have been derived from Shamo traditional fighting cocks, Molecular Phylogenetics and Evolution, vol. 33, no. 1, pp. 16-21, 2004. doi: 10.1016/j.ympev.2004.04.019 
10. C. Elkhoraibi, R. Blatchford, M. Pitesky and J. Mench, Backyard chickens in the United States: A survey of flock owners, Poultry Science, vol. 93, no. 11, pp. 2920-2931, 2014. doi: 10.3382/ps.2014-04154

11. W. Lv et al., Explore the potential effect of natural herbals to resist Newcastle Disease Virus, Poultry Science, vol. 98, no. 5, pp. 1993-1999, 2019. doi: $10.3382 / \mathrm{ps} /$ pey557

12. F. Bradley, Biosecurity: Educational Programs, Journal of Applied Poultry Research, vol. 16, no. 1, pp. 77-81, 2007. doi: 10.1093/japr/16.1.77

13. K. Pepin et al., Using quantitative disease dynamics as a tool for guiding response to avian influenza in poultry in the United States of America, Preventive Veterinary Medicine, vol. 113, no. 4, pp. 376-397, 2014. doi: 10.1016/j.prevetmed.2013.11.011

14. The Best Conditioning Method for Gamefowls Competing In the Long Knife, 1st ed. Philippines, 2018.

15. E. Paul, J. Edgar, G. Caplen and C. Nicol, Examining affective structure in chickens: valence, intensity, persistence and generalization measured using a Conditioned Place Preference Test, Applied Animal Behaviour Science, vol. 207, pp. 39-48, 2018. doi: 10.1016/j.applanim.2018.07.007

16. A. Alon, An Inference Approach of Flood Level Detection and Alert System: Flood-Induced Simulated Environment, International Journal of Advanced Trends in Computer Science and Engineering, vol. 9, no. 2, pp. 2259-2264, 2020. doi: 10.30534/ijatcse/2020/205922020

17. M. F. Malbog, Hybrid-FireID: Fire Identification using Hybrid Features Extraction for Combustible and Fluid Fire Segmentation, International Journal of Emerging Trends in Engineering Research, vol. 8, no. 2, pp. 471-475, 2020. doi: 10.30534/ijeter/2020/35822020

18. J. Nicolas-Mindoro, NotiPoy: Early Notification of Detected Fire Using Image Processing Applying Convolutional Neural Network, International Journal of Advanced Trends in Computer Science and Engineering, vol. 8, no. 6, pp. 2811-2816, 2019. doi: 10.30534/ijatcse/2019/21862019

19. A. Alon, An Image Processing Approach of Multiple Eggs' Quality Inspection, International Journal of Advanced Trends in Computer Science and Engineering, vol. 8, no. 6, pp. 2794-2799, 2019. doi: 10.30534/ijatcse/2019/18862019

20. A. Alon, E. Festijo and D. Juanico, Tree Detection using Genus-Specific RetinaNet from Orthophoto for Segmentation Access of Airborne LiDAR Data, 2019 IEEE 6th International Conference on Engineering Technologies and Applied Sciences (ICETAS), 2019. doi: 10.1109/icetas48360.2019.9117495 